\title{
Patient-Reported Side Effects of Intradetrusor Botulinum Toxin Type A for Idiopathic Overactive Bladder Syndrome
}

\author{
Ricarda M. Bauer Christian Gratzke Alexander Roosen Yasmin Hocaoglu \\ Margit E. Mayer Alexander Buchner Christian G. Stief Florian May \\ Department of Urology, Ludwig Maximilian University, Munich, Germany
}

\section{Key Words}

Botulinum toxin $\cdot$ Botulinum toxin, side effects $\cdot$ Botox ${ }^{\circledR}$. Dysport $^{\circledR} \cdot$ Idiopathic overactive bladder $\cdot$ Intradetrusor injection

\begin{abstract}
Objective: The aim of the study was a prospective assessment of patient-reported side effects in an open-label study after intradetrusor botulinum toxin injections for idiopathic overactive bladder (OAB). Patients and Methods: Botulinum toxin $A$ injection was performed in 56 patients with idiopathic OAB. Patients were followed up for 6 months concerning side effects and patients' satisfaction. Results: Different types of side effects were assessed such as dry mouth (19.6\%), arm weakness (8.9\%), eyelid weakness (8.9\%), leg weakness (7.1\%), torso weakness (5.4\%), impaired vision (5.4\%) and dysphagia (5.4\%). In all cases, symptoms were mild and transient. Urological complications such as gross hematuria (17.9\%), acute urinary retention (8.9\%) and acute urinary tract infection (7.1\%) were noticed. In all cases, acute urinary retention was transient and treated with temporary intermittent selfcatheterization. There was no statistically significant correlation between dosage and observed side effects. Patients' satisfaction rate was high (71.4\%). Conclusion: Intradetrusor injection of botulinum toxin was associated with a high rate of neurourological side effects. In general, side effects were transient, mild and did not require special treatment.
\end{abstract}

Copyright $\odot 2010$ S. Karger AG, Basel

\section{KARGER}

Fax +4161306 1234 E-Mail karger@karger.ch www.karger.com
(C) 2010 S. Karger AG, Basel

0042-1138/11/0861-0068\$38.00/0

Accessible online at:

www.karger.com/uin

\section{Introduction}

The overactive bladder $(\mathrm{OAB})$ syndrome has a prevalence of $11.8 \%$ and is characterized by urgency, with or without urge incontinence and usually with frequency and nocturia [1]. Men and women are equally affected with a high impact on quality of life, work productivity and sexual life [2]. In addition, OAB is a high economic burden and the prevalence increases with age [3]. If no neurogenic cause for the bladder dysfunction like Parkinson disease, spinal cord injuries, spinal cord stenosis or diabetes mellitus exists, the causative reason for the $\mathrm{OAB}$ symptoms often remains unclear. In these cases, the OAB is called non-neurogenic or idiopathic. Standard treatment options for $\mathrm{OAB}$ are antimuscarinics and bladder training. However, in some patients antimuscarinic treatment fails, contraindications for antimuscarinics exist or the antimuscarinics trigger severe side effects. In the past, for these patients invasive surgery (mainly bladder augmentation) was the only available treatment option. Intradetrusor injection of botulinum toxin represents an alternative and minimally invasive treatment option for these patients with good results even after repeated injections [4-9]. As of yet, botulinum toxin is not licensed for the use in $\mathrm{OAB}$ patients and the optimum dose for intradetrusor injections is not defined [10].

In numerous studies, the efficacy of botulinum toxin in patients with idiopathic $\mathrm{OAB}$ was examined and

Dr. med. Ricarda M. Bauer

Department of Urology, Ludwig Maximilian University

Marchioninistrasse 15, DE-81377 Munich (Germany)

Tel. +4989709 50, Fax +49 8918975536

E-Mail Ricarda.Bauer@med.uni-muenchen.de 


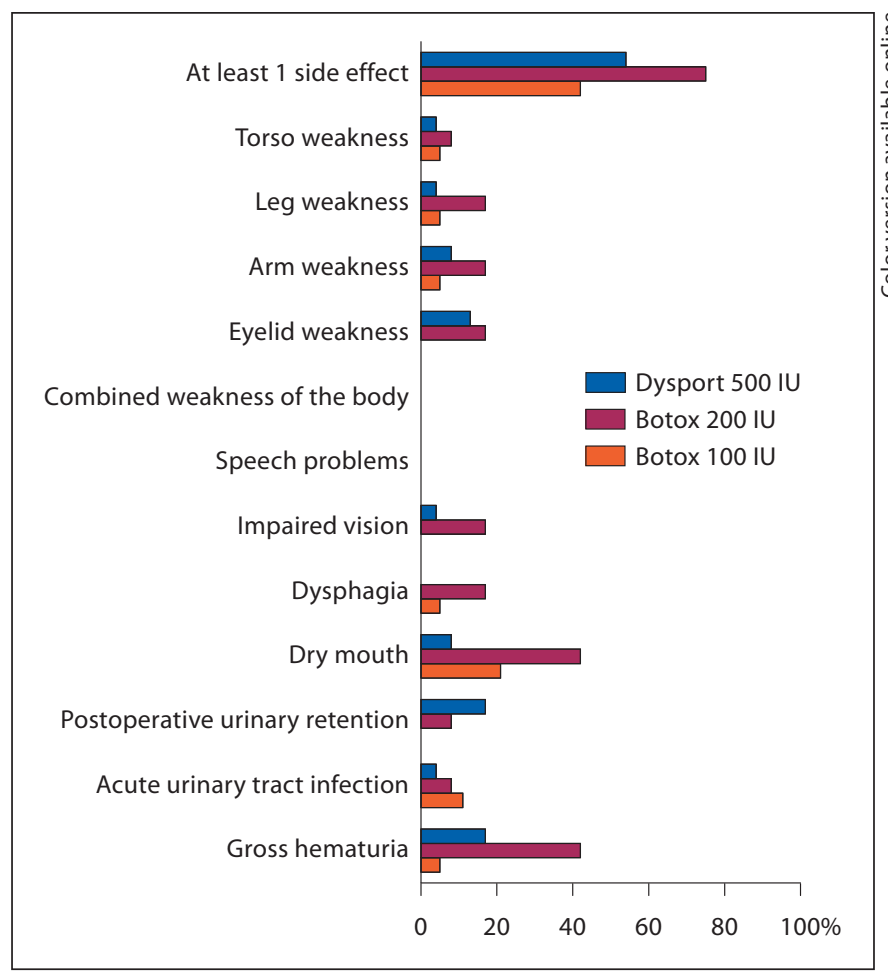

Fig. 1. Side effects correlated to the amount of botulinum toxin $\mathrm{A}$ injected.

showed significant improvement of OAB symptoms [6, 11-15]. In most cases, the authors reported urological side effects or complications like urinary retention and urinary tract infection (UTI). However, data are lacking regarding systemic side effects. Only a few studies analyzed this complication [11,15-17], and no quantitative data are given. Therefore, the aim of the present study was to assess side effects after intradetrusor injections of botulinum toxin type $\mathrm{A}$ in patients with refractory idiopathic $\mathrm{OAB}$.

\section{Patients and Methods}

Between June 2007 and February 2009, 56 consecutive patients with refractory idiopathic $\mathrm{OAB}$ were treated with botulinum toxin type $\mathrm{A}$ in a prospective clinical study. Botulinum toxin was injected at 20 sites in the detrusor vesicae. All patients received antibiotics for 3 days postoperatively. We used Dysport ${ }^{\circledR} 500$ IU (Ipsen Ltd) or Botox ${ }^{\circledR}$ 100, 150 and 200 IU (Allergan Ltd).

Preoperatively, urodynamic assessment, ultrasound for residual urine and urine analysis were performed. Patients with neurogenic $\mathrm{OAB}$, residual urine $>50 \mathrm{ml}$ and patients with acute urinary infections were excluded from this study. Further, patients with less than two failed treatment trials with antimuscarinics at therapeutic dosage for a minimum of 6 months were excluded.
However, we included patients who were not able to take antimuscarinics because of severe side effects or contraindications for antimuscarinics. Patient age was $41-87$ years (mean 65$)$. 41 patients were female (73.2\%) and 15 male $(26.8 \%)$

Postoperatively, patients had ultrasound for residual urine before discharge. Patients with acute postoperative urinary retention (residual urine $>100 \mathrm{ml}$ ) were trained in intermittent selfcatheterization (ISC). ISC was stopped when residual urine was $<100 \mathrm{ml}$. One week after discharge, urinalysis was performed to rule out acute urinary infection. Ultrasound for residual urine was performed at 1 week, 6 weeks, 3 and 6 months postoperatively. In addition, patients were interviewed concerning side effects of botulinum toxin: gross hematuria, dry mouth, dysphagia, speech problems, impaired vision, eyelid weakness, arm weakness, leg weakness, torso weakness and combined weakness of the whole body. After 6 months, patients were interviewed concerning overall treatment satisfaction.

\section{Statistical Analysis}

p values $<0.05$ were considered significant. All statistical analyses were performed using Statistica for Windows, release 8 (StatSoft, Tulsa, Okla., USA). The $\chi^{2}$ test was used to analyze the influence of various botulinum toxin doses on side effects.

\section{Results}

At least one side effect occurred in $53.6 \%$ of the patients (fig. 1).

\section{Acute Postoperative Urinary Retention}

In 5 patients $(8.9 \%)$ a residual urine of $>100 \mathrm{ml}$ was detected. These patients performed ISC for a mean of 41 days (range 6-56). There was no statistically significant correlation between postoperative residual urine and the botulinum toxin dose injected $(\mathrm{p}=0.292)$.

\section{Postoperative Gross Hematuria}

In 10 patients (17.9\%), gross hematuria occurred after injection and disappeared in all cases without further treatment after at least 7 days. In all cases, hematuria was only mild and patients needed no further investigation or treatment. There was no statistically significant correlation between postoperative gross hematuria and the injected dose $(\mathrm{p}=0.074)$.

\section{Postoperative Acute Urinary Tract Infection}

Urinanalysis 1 week after botulinum toxin injection showed symptomatic UTI in 4 patients (7.1\%) and was treated with oral antibiotics. No patient showed recurrent infections. There was no statistically significant correlation between postoperative acute UTI and the injected dose $(\mathrm{p}=0.861)$. 


\section{Dry Mouth, Dysphagia and Speech Disorders}

Eleven patients (19.6\%) complained of a dry mouth and 3 patients (5.4\%) had dysphagia additionally due to their dry mouth (27.3\% of the patients with dry mouth). There were no cases of speech disorders. In all cases, the symptoms were mild and the patients handled the dry mouth with an increased intake of daily fluid. The dry mouth disappeared after a mean of 19 days (range 7-31). There was no statistically significant correlation between dry mouth $(\mathrm{p}=0.117)$ or dysphagia $(\mathrm{p}=0.217)$ and the injected dose.

\section{Impaired Vision and Eyelid Weakness}

Three patients (5.4\%) complained of impaired vision and 5 patients $(8.9 \%)$ of eyelid weakness. In all cases, the symptoms were mild and patients needed no further investigation or treatment. Impaired vision disappeared after a mean of 5 days (range 3-14) and eyelid weakness after a mean of 17 days (range 3-41). There was no statistically significant correlation between impaired vision $(p=0.238)$ or eyelid weakness $(p=0.359)$ and the injected dose.

\section{Arm, Leg, Torso and Combined Weakness of the \\ Whole Body}

Five patients (8.9\%) complained of arm weakness for a mean of 45 days (range 15-68). Four patients (7.1\%) complained of leg weakness for a mean of 41 days (range 1260). Three patients (5.4\%) complained of torso weakness for a mean of 21 days (range 7-35). There was no combined muscle weakness of the whole body. Symptoms were mild in all cases. Patients were presented to a neurologist, but no special treatment was necessary. There was no statistically significant correlation between muscle weakness and the injected dose (arm: $p=0.728$, leg: $\mathrm{p}=0.544$, torso: $\mathrm{p}=0.954$ ).

\section{Satisfaction}

$71.4 \%$ of the patients were satisfied or very satisfied with the injection of botulinum toxin (fig. 2). Overall, patients with side effects had a lower satisfaction rate than patients without side effects.

\section{Discussion}

In the present study, 56 patients with idiopathic $\mathrm{OAB}$ syndrome were treated with intradetrusor injection of botulinum toxin type A. 53.6\% of the patients presented with at least one side effect. Main side effects were dry

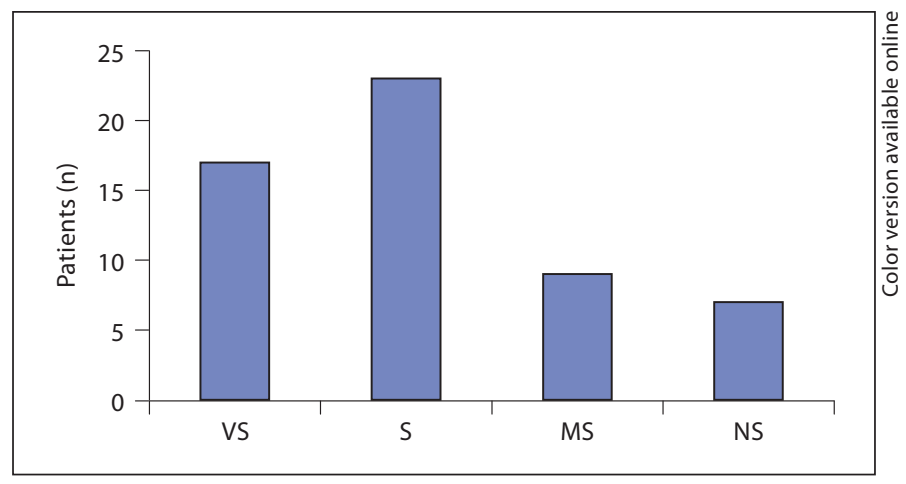

Fig. 2. Patients' satisfaction 6 months after injection of botulinum toxin. VS = Very satisfied; $\mathrm{S}$ = satisfied; $\mathrm{MS}$ = moderately satisfied; NS $=$ not satisfied.

mouth (19.6\%), gross hematuria (17.9\%), acute postoperative urinary retention $(8.9 \%)$, weakness of the arms (8.9\%) and eyelid weakness (8.9\%). Postoperative acute UTI occurred in $7.1 \%$ of the cases. In all cases except acute urinary retention and infection, symptoms were mild, transient and no further investigation or treatment was necessary. Acute urinary retention was transient in all cases and was treated with ISC. There was no statistically significant correlation between botulinum toxin doses and side effects. Patients' satisfaction rate was high (71.4\% satisfied or very satisfied).

The UTI rate varies strongly regarding different series from $6.5 \%$ up to $44 \%$ [18]. In comparison, we found a comparably low rate of postoperative acute UTIs (7.1\%). This may be due to antibiotic prophylaxis during surgery and the continuation of oral antibiotics for 3 days in our series which probably decreased the rate of UTIs diagnosed.

Given the mechanism of action of botulinum toxin, it is not surprising that some patients experience urinary retention. However, analysis of data concerning urinary retention and residual urine represents a difficult problem. Definition of acute urinary retention and the indication for ISC varies from study to study. In our series, patients with residual urine $>100 \mathrm{ml}$ were trained in ISC. Three patients $\left(2 \times 500\right.$ IU Dysport ${ }^{\circledR}, 1 \times 200$ IU Botox ${ }^{\circledR}$ ) were not able to empty the bladder spontaneously and required intermittent catheterization at 3 weeks. The remaining 2 subjects experienced postvoid residual urine values greater than $20 \%$ of their bladder capacity at the 3 -week evaluation. These complications are consistent with those reported by other authors. Flynn et al. [5] measured in $26 \%$ residual urine of $\geq 200 \mathrm{ml}$ in a placebo- 
controlled study. Popat et al. [17] reported in $19.3 \%$ residual urine necessitating ISC after injection of $200 \mathrm{IU}$ Botox $^{\circledR}$. In another placebo-controlled study, residual urine increased in $43 \%$ after injection of 200 IU botulinum toxin [11]. In contrast, the placebo group of this series showed no increase of residual urine.

Overall, the risk of developing significant residual urine or acute urinary retention seems to increase with higher doses of injected botulinum toxin [19]. In addition, patients with neurogenic OAB suffer more often from urinary retention after botulinum $A$ injections into the bladder [17]. However, we were not able to show a dose relation regarding postoperative urinary retention. This may be due to the fact that we did not inject high botulinum doses and excluded patients with neurogenic $O A B$ from this series.

There are only limited data available concerning neurological side effects. Jeffery et al. [16] report on 1 of 25 patients (4\%) who suffered from general muscle weakness after botulinum toxin injection. Sahai et al. [15] investigated muscle weakness after botulinum toxin injection in the bladder and noticed no generalized muscle weakness necessitating admission. However, this study does not mention mild muscle weakness. Brubaker et al. [11] report serious adverse events, including non-urinary infection, cardiovascular, neurological and musculoskeletal system injury in the botulinum toxin group ( 3 of 28 patients) as well as in the placebo group ( 2 of 15 patients). In addition, 6 unexpected adverse events including gastrointestinal complications occurred in the botulinum toxin group. A detailed work-up of these adverse events is missing.

Our data are limited by the fact that the assessment of non-urological side effects was based on patient questionnaires and that there is no placebo arm. This measurement is subjective and might induce bias. Another limitation is the relatively small number of patients. However, most series included less cases and only a few studies report on more than 100 patients $[6,20,21]$.

Overall, patients reported a surprisingly high rate of neurological side effects which were mild, transient and did not require further treatment. The patients described here, who suffered from muscle weakness after treatment for bladder overactivity with injection of botulinum toxin in the detrusor muscles, received different types of botulinum toxin. The pathogenesis of side effects in our patients remains unclear. The bladder wall, especially between trabeculation bars, may have been too thin so that diffusion perivesically occurred together with a limitation of the local effect.

Side Effects of Intradetrusor Botulinum Toxin Type A for OAB Syndrome
Hematological spread by inadvertent delivery of the toxin into a blood vessel may be another reason. However, we did not find gross hematuria in these patients. Diffusion of botulinum toxin within the injected muscle and into adjacent muscles has been well documented [22]. Retrograde axonal transport represents another possibility [23]. Weakness or pathological EMG changes in muscles distal to the injection site have been reported in different applications [24].

A particular product or batch of the toxin cannot be blamed as our patients received toxins from different batches and manufacturers. The frequency of side effects did not differ significantly between Dysport ${ }^{\circledR}$ and Botox ${ }^{\circledR}$, although data showed a tendency towards more side effects after treatment with 200 IU Botox ${ }^{\circledR}$. The total doses used in our patients were within the range generally recommended. Although none of our patients showing side effects received repeated injections, it may be speculated that repeated treatments may have an impact on toxin binding and diffusion, because functional recovery of poisoned cells is achieved by means of sprouting of new motor axon terminals. It is conceivable that botulinum toxin binding is impaired and uptake of botulinum toxin after repeated injections could take place at some distance from the injection site. The safety of repeated injections is rarely or not described. To minimize the risk of immune resistance and response as much as possible, it is advisable to wait at least 3 months between injections, and to choose the lowest dose that will achieve the desired effect [8].

\section{Conclusion}

We have described a high rate of neurourological side effects after intradetrusor botulinum toxin injections. The cause is most likely presynaptic inhibition due to systemic spread of the toxin. Which patients have a particular risk of developing this complication remains to be determined. Caution is needed in patients with impaired neurotransmission such as with myasthenia gravis, or taking drugs that may interfere with neurotransmission [24]. There is a definite need for close observation of general effects and for studies on the optimal dose and the optimal injection technique in this type of treatment. Meanwhile, patients should be warned that temporary general side effects may occur.

Urol Int 2011;86:68-72 


\section{References}

1 Irwin DE, Milsom I, Hunskaar S, Reilly K, Kopp Z, Herschorn S, Coyne K, Kelleher C, Hampel C, Artibani W, Abrams P: Population-based survey of urinary incontinence, overactive bladder, and other lower urinary tract symptoms in five countries: results of the EPIC study. Eur Urol 2006;50:1306-1314.

2 Coyne KS, Sexton CC, Irwin DE, Kopp ZS, Kelleher CJ, Milsom I: The impact of overactive bladder, incontinence and other lower urinary tract symptoms on quality of life, work productivity, sexuality and emotional well-being in men and women: results from the EPIC study. BJU Int 2008;101:1388-1395.

3 Irwin DE, Mungapen L, Milsom I, Kopp Z, Reeves P, Kelleher C: The economic impact of overactive bladder syndrome in six western countries. BJU Int 2009;103:202-209.

4 Andersson KE, Chapple CR, Cardozo L, Cruz F, Hashim H, Michel MC, Tannenbaum C, Wein AJ: Pharmacological treatment of overactive bladder: Report from the international consultation on incontinence. Curr Opin Urol 2009;19:380-394.

5 Flynn MK, Amundsen CL, Perevich M, Liu F, Webster GD: Outcome of a randomized, double-blind, placebo-controlled trial of botulinum a toxin for refractory overactive bladder. J Urol 2009; 181:2608-2615.

6 Schmid DM, Sauermann P, Werner M, Schuessler B, Blick N, Muentener M, Strebel RT, Perucchini D, Scheiner D, Schaer G, John H, Reitz A, Hauri D, Schurch B: Experience with 100 cases treated with botulinum A toxin injections in the detrusor muscle for idiopathic overactive bladder syndrome refractory to anticholinergics. J Urol 2006;176: 177-185.

7 Schurch B: Botulinum toxin for the management of bladder dysfunction. Drugs 2006;66: 1301-1318.
8 Leong RK, De Wachter SG, van Kerrebroeck PE: Current information on sacral neuromodulation and botulinum toxin treatment for refractory idiopathic overactive bladder syndrome: a review. Urol Int 2010;84:245253.

9 Stoehrer M, Wolff A, Kramer G, Steiner R, Lmochner-Ernst D, Leuth D, Steude U, Ruebben H: Treatment of neurogenic detrusor overactivity with botulinum toxin A: the first seven years. Urol Int 2009;83:379-385.

10 Cohen BL, Barboglio P, Rodriguez D, Gousse AE: Preliminary results of a dose-finding study for botulinum toxin $\mathrm{A}$ in patients with idiopathic overactive bladder: 100 versus 150 units. Neurourol Urodyn 2009;28:205-208.

11 Brubaker L, Richter HE, Visco A, Mahajan S, Nygaard I, Braun TM, Barber MD, Menefee S, Schaffer J, Weber AM, Wei J: Refractory idiopathic urge urinary incontinence and botulinum a injection. J Urol 2008; 180:217222.

12 Chancellor MB: Ten years single surgeon experience with botulinum toxin in the urinary tract; clinical observations and research discovery. Int Urol Nephrol 2010; 42:383-391.

13 Kuo HC: Comparison of effectiveness of detrusor, suburothelial and bladder base injections of botulinum toxin A for idiopathic detrusor overactivity. J Urol 2007;178:13591363.

14 Mohanty NK, Nayak RL, Alam M, Arora RP: Role of botulinum toxin A in management of refractory idiopathic detrusor overactive bladder: single-center experience. Indian J Urol 2008;24:182-185.

15 Sahai A, Khan MS, Dasgupta P: Efficacy of botulinum toxin A for treating idiopathic detrusor overactivity: results from a singlecenter, randomized, double-blind, placebocontrolled trial. J Urol 2007;177:2231-2236.

16 Jeffery S, Fynes M, Lee F, Wang K, Williams L, Morley R: Efficacy and complications of intradetrusor injection with botulinum toxin $\mathrm{A}$ in patients with refractory idiopathic detrusor overactivity. BJU Int 2007;100: 1302-1306.
17 Popat R, Apostolidis A, Kalsi V, Gonzales G, Fowler CJ, Dasgupta P: A comparison between the response of patients with idiopathic detrusor overactivity and neurogenic detrusor overactivity to the first intradetrusor injection of botulinum A toxin. J Urol 2005; 174:984-989.

18 Mehnert U, Schurch B: Botulinum toxin in non-neurogenic bladder dysfunction (in German). Urologe 2009;48:233-244.

19 Shaban AM, Drake MJ: Botulinum toxin treatment for overactive bladder: risk of urinary retention. Curr Urol Rep 2008;9:445451.

20 Kalsi V, Popat RB, Apostolidis A, Kavia R, Odeyemi IA, Dakin HA, Warner J, Elneil S, Fowler CJ, Dasgupta P: Cost-consequence analysis evaluating the use of botulinum neurotoxin A in patients with detrusor overactivity based on clinical outcomes observed at a single UK centre. Eur Urol 2006;49:519527.

21 Smith CP, Nishiguchi J, O'Leary M, Yoshimura N, Chancellor MB: Single-institution experience in 110 patients with botulinum toxin A injection into bladder or urethra. Urology 2005;65:37-41.

22 Eleopra R, Tugnoli V, Caniatti L, De Grandis D: Botulinum toxin treatment in the facial muscles of humans: evidence of an action in untreated near muscles by peripheral local diffusion. Neurology 1996;46:1158-1160.

23 Garner CG, Straube A, Witt TN, Gasser T, Oertel WH: Time course of distant effects of local injections of botulinum toxin. Mov Disord 1993;8:33-37.

24 Lange DJ, Brin MF, Fahn S, Lovelace RE: Distant effects of locally injected botulinum toxin: Incidence and course. Adv Neurol 1988;50:609-613. 